\title{
Frequency of occurrence, mode of development, and . significance of rice bodies in rheumatoid joints
}

\author{
A. J. POPERT, ${ }^{1}$ D. L. SCOTT ${ }^{2}$ A. C. WAINWRIGHT ${ }^{2} \mathrm{~K} . \mathrm{W} \cdot \mathrm{W}$ A LTON,${ }^{2}$ \\ N. WILLIAMSON, ${ }^{2 *}$ AND J.H. CHAPMAN ${ }^{1}$ \\ From ${ }^{1}$ Highfield Hospital, Droitwich, Worcestershire, and the ${ }^{2}$ Department of Investigative Pathology, \\ Rheumatism Research Wing, University of Birmingham
}

SUMMARY The incidence of rice bodies (RB) in synovial effusions has been studied in 36 patients with rheumatoid arthritis (RA) and in 12 patients with seronegative inflammatory arthritis ( 7 cases of Still's disease, 3 of psoriatic arthritis, and 2 of ankylosing spondylitis). In the RA group 50 joints were aspirated before and after saline lavage with a specially designed wide-bore needle. RB were found in $72 \%$ overall of the joints studied in this group, $14 \%$ on initial simple aspiration and an additional $58 \%$ after lavage. In contrast no rice bodies were found in 31 aspirations with lavage by an identical technique in the 12 patients with seronegative synovitis. The RB in RA synovitis occurred both early and late in the course of the disease and were not related to the severity of clinical or radiological changes. However, removal of rice bodies was accompanied by clinical improvement and reduction of synovitis. Macroscopically RB varied in shape and size, some being so large as to preclude effective removal by needles of the gauge customarily employed for joint aspirations. Microscopically the majority of RB were composed of coarsely reticular material reacting immunologically with antifibrinogen and antifibronectin and containing mononuclear cells. Some showed vacuolation suggestive of fibrinolysis, but many showed organisation like that seen in established connective tissues, with the formation of mature collagen, reticulin, and elastin. These findings are discussed in relation to the origin, development, and significance of rice bodies in rheumatoid synovitis.

Intra-articular 'rice bodies' were first described in association with tuberculous arthritis ${ }^{1}$ but are now more commonly encountered in other arthritides, including rheumatoid arthritis (RA). Their appellation derives from their alleged naked eye resemblance to grains of polished rice, but in fact these particles are markedly variable in size, shape, and consistency.

Previous studies on their nature in $\mathrm{RA}^{23}$ have not defined adequately their frequency, relation to clinical symptoms, or mode of origin, so that there is a tendency to consider them to be uncommon and of relatively little significance. We present observations which might necessitate the revision of such conclusions.

Accepted for publication 17 March 1981.

*Present address: National Blood Transfusion Service, Lancaster Centre, Lancaster LA1 3JP.

Correspondence to Professor K. W. Walton, Department of Investigative Pathology, Medical School, Rheumatism Research Wing, University of Birmingham, Birmingham B15 2JP.

\section{Materials and methods}

Fifty consecutive joint aspirations and lavage (performed as described below) were carried out in 36 patients with classical or definite RA as judged by the criteria of the American Rheumatism Association. ${ }^{4}$ Details of the patients are summarised in Table 1. Five of these patients had additional diagnoses of osteoarthrosis (3), chondrocalcinosis (1), and septic arthritis (1). Forty-nine of the aspirations were made from knee joints and 1 from a shoulder joint. The mean duration of symptoms was 6.9 years (range 1-12 years). Plain radiographs of the affected joint were made prior to aspiration. Details were recorded

Table 1 Details of patients with rheumatoid arthritis in the study.

\begin{tabular}{lllll}
\hline $\begin{array}{l}\text { Number } \\
\text { Sex ratio } \\
(M: F)\end{array}$ & $\begin{array}{l}\text { Age, } \\
y r(S D)\end{array}$ & $\begin{array}{l}\text { Disease duration, } \\
y r(S D)\end{array}$ & $\begin{array}{l}\text { SCAT titre } \\
1 / 32\end{array}$ \\
\hline 36 & $10: 26$ & $58.4(12 \cdot 1)$ & $12.9(11 \cdot 4)$ & $27(75 \%)$ \\
\hline
\end{tabular}




\section{Popert, Scott, Wainwright, Walton, Williamson, Chapman}

of the volume of the effusion, the temperature of the joint, and the extent of synovial thickening. Arthrograms were performed in several selected cases. In addition 31 aspirations and lavage were carried out by the same method in 12 patients with inflammatory seronegative arthritis of the knee joint; 7 had Still's disease, 3 psoriatic arthritis, and 2 ankylosing spondylitis. Six were male and 6 female, and they were aged 9-52 years.

Methods of aspiration and lavage. An 8-14 gauge modified spinal needle with a short bevel was introduced medially or laterally into the knee joint, or anteriorly into the shoulder-joint, under local anaesthesia (2\% lignocaine) with aseptic technique. In most cases a 10 or 12 gauge needle was found to be most suitable. Any fluid and any rice bodies aspirated were retained. Lavage was performed with $50-100$ $\mathrm{ml}$ of sterile $0.9 \%$ saline at $24^{\circ} \mathrm{C}$. Any additional rice bodies removed were retained. The volumes of synovial fluid and of the rice bodies (by displacement) were measured and recorded.

Histological techniques. Particulate material from joints was examined after fixation in $10 \%$ formol saline and embedding in paraffin wax. In some instances material was also examined by conventional histological techniques and immunohistologically as frozen sections of fresh unfixed material, or after fixation in cold ethanol by the method of Saint-Marie. ${ }^{5}$ The immunohistological reagents and methods used have been previously described. ${ }^{6}$

Histological staining methods. Sections were examined after staining with haematoxylin and eosin ( $\mathrm{H}$ and $\mathrm{E})$; haematoxylin and van Gieson's fluid (HVG); Miller's modification ${ }^{7}$ of Weigert's elastictissue stain; Gordon and Sweet's method ${ }^{8}$ for reticulin; the Martius scarlet/blue (MSB) technique for fibrin of Lendrum et al. ${ }^{9}$; the picropolychrome method of Herovici ${ }^{10}$; or with phosphotungstic acid haematoxylin (PTAH). In selected instances, sections were also examined after staining with haematoxylin and oil red $\mathrm{O}$ for lipid; Congo red for amyloid; and by the periodic acid Schiff method, with alcian blue, or by the dialysed iron method, for carbohydrates.

\section{Results}

INCIDENCE OF RICE BODIES AND THEIR

RELATION TO CLINICAL SYMPTOMS

Rice bodies were found to be common in rheumatoid synovitis. The incidence found in our patients is given in Table 2. It can be seen from this that lavage plus aspiration, as opposed to the initial simple aspiration alone, markedly increased the yield of rice bodies. Rice bodies were found both early and late in relation to the history of symptomatic involvement of joints. Both joints with normal radiographic appearances and those with gross erosive changes and marked cartilage loss were found to contain rice bodies. No simple relation was found between the presence of rice bodies and the radiographic or the clinical (size of effusion, temperature of joint, or extent of synovial thickening) assessment of the severity of joint disease. Similarly no correlation was obtained with seropositivity (Rose-Waaler titre 1:32 or greater).

On the other hand the removal of rice bodies effected symptomatic relief and reduction of synovitis. ${ }^{11}$ This observation suggested that the persistence of rice bodies within the joint probably contributes directly to the chronicity of synovitis (also, see 'Discussion').

Rice bodies are occasionally detectable without their physical removal from a joint in that they can sometimes be seen by arthrography. However, only relatively large particles can thus be visualised, and this procedure, we felt, could be justified ethically only where there were other indications for its use, so it was not applied in all our cases.

In contrast to the patients with RA no rice bodies were found in 31 aspirations and lavage of the knee joints of the 12 patients with other inflammatory arthropathies. The mean volume of synovial fluid

Table 2 Incidence of rice bodies.

\begin{tabular}{|c|c|c|c|c|c|c|}
\hline & \multicolumn{4}{|c|}{ Rheumatoid arthritis (50 aspirations and lavage) } & \multicolumn{2}{|c|}{$\begin{array}{l}\text { Seronegative in flammatory arthritis } \\
\text { (31 aspirates and lavage) }\end{array}$} \\
\hline & \multicolumn{3}{|c|}{ Synovial fluid containing rice bodies } & \multirow[t]{2}{*}{ No rice bodies } & \multirow{2}{*}{$\begin{array}{l}\text { Synovial fluid } \\
\text { containing rice } \\
\text { bodies }\end{array}$} & \multirow[t]{2}{*}{ No rice bodies } \\
\hline & In simple aspirate & $\begin{array}{l}\text { Additional recovery } \\
\text { with lavage }\end{array}$ & Total & & & \\
\hline \multirow{3}{*}{$\begin{array}{l}\text { Per cent cases } \\
\text { Mean vol. ( } \mathrm{ml} \text { ) of rice } \\
\text { bodies and range } \\
\text { Mean vol ( } \mathrm{ml} \text { ) of } \\
\text { synovial fluid and } \\
\text { range }\end{array}$} & $14 \%$ & $58 \%$ & $72 \%$ & $28 \%$ & $\mathbf{0}$ & $100 \%$ \\
\hline & $6 \cdot 0(3-9)$ & $3 \cdot 0(1-16)$ & $3 \cdot 6(1-16)$ & 0 & 0 & 0 \\
\hline & $23 \cdot 0(6-70)$ & $10 \cdot 0(9-25)$ & $12 \cdot 5(6-70)$ & $21 \cdot 0(5-65)$ & 0 & $18 \cdot 0(1-110)$ \\
\hline
\end{tabular}


removed in these patients was $18 \mathrm{ml}$ (range $1-110 \mathrm{ml})$.

\section{MACROSCOPIC APPEARANCES}

The material aspirated showed marked variation in the consistency, shape, and size of the particles present. The greatest diameter of the majority of the particles exceeded $7 \mathrm{~mm}$ in $10 \%$ of cases; ranged between 2 and $7 \mathrm{~mm}$ in 55\% of cases; and was less than $2 \mathrm{~mm}$ in the remaining $35 \%$. The particles were sometimes white and bore some resemblance to rice grains but were also sometimes yellowish and irregular in shape or thread-like in appearance. The variation in size and shape of the particles is illustrated in Fig. 1.

\section{MICROS COPIC APPEARANCES}

Observations previously made $\mathrm{I}^{\mathbf{3} 612}$ were confirmed and extended. The heterogeneity of the material aspirated after lavage of joints was further revealed by microscopic examination in that occasional fragments easily identifiable as bone, cartilage, or shreds of synovial villi were seen in the aspirate (Fig. 2). Rounded structures composed of a vascularised collagenous core (presumptively derived from synovium) were also seen to be superficially coated by fibrin (Fig. 3). However, the bulk of the specimens in aspirates made from acute and chronic synovial effusions consisted simply of amorphous or coarsely reticular and condensed fibrin, as judged by conventional staining characteristics (Figs. 2 and 4). For

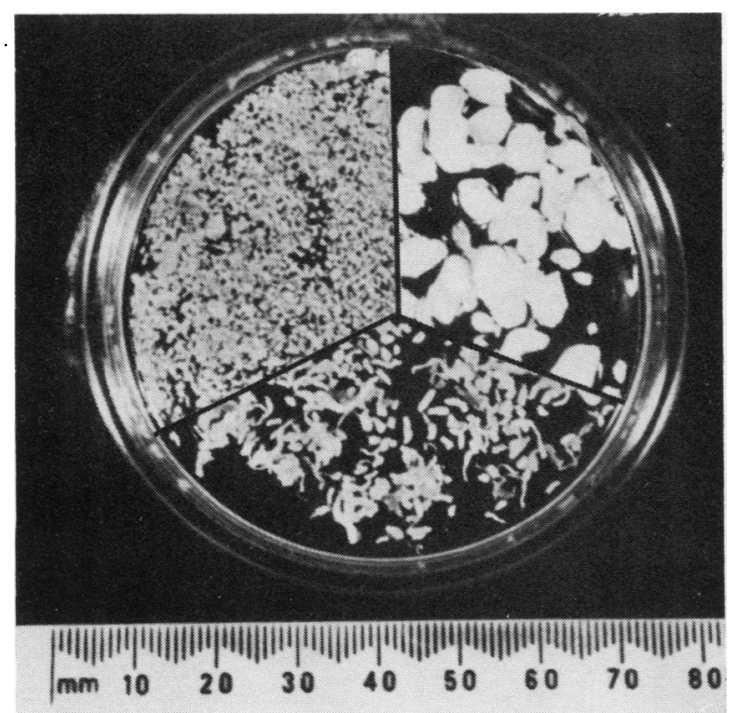

Fig. 1 Composite picture of rice bodies, photographed at the same magnification, to show particles of 3 different size ranges. example, the material was brightly eosinophilic in sections stained with haematoxylin and eosin, stained yellow with HVG or the picropolychrome method, brilliant scarlet with the MSB technique, and dark purplish blue with PTAH.

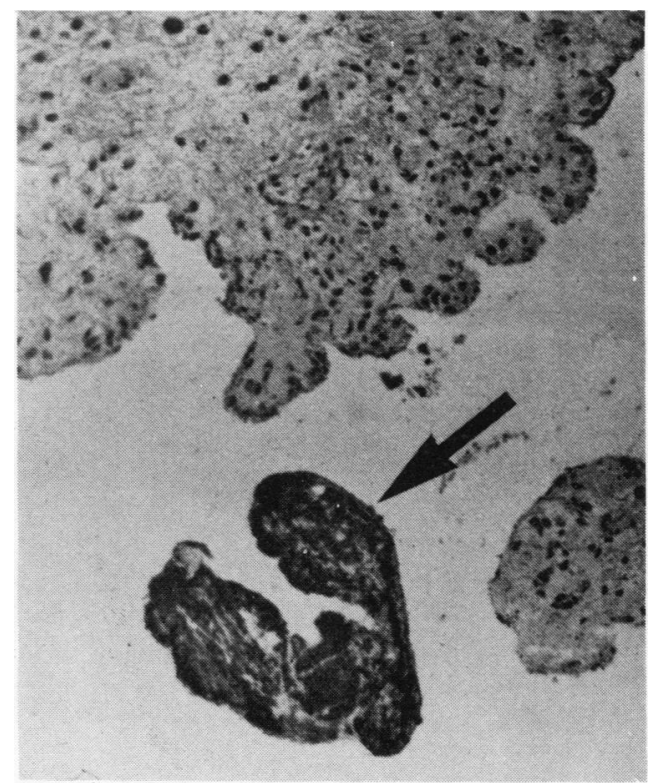

Fig. 2 Deposit from aspirate after lavage of knee-joint. Two fragments of synovial membrane and irregularly shaped particle composed of condensed fibrin (arrow) (MSB, $\times 125)$.

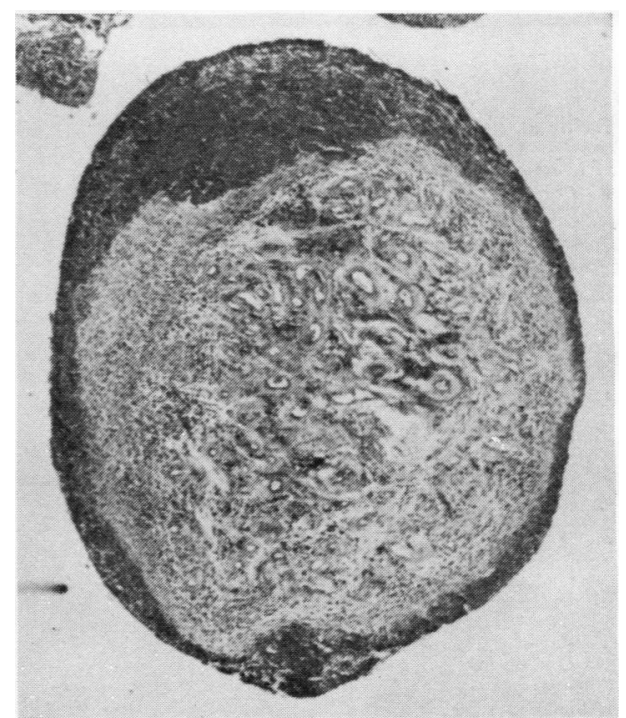

Fig. 3 Vascularised nodule (probably derived from synovium) with outer covering of fibrinous deposit ( $H$ and $E$, $\times 125$ ). 


\section{Popert, Scott, Wainwright, Walton, Williamson, Chapman}

In fresh unfixed specimens, or in material fixed in cold ethanol from the same patients as those described above, the nature of the material was confirmed immunologically with antifibrinogen labelled with fluorescein or with horse radish peroxidase (Figs. 5 and 7B). In addition, in sections made of fresh or similarly fixed material from these subjects after treatment with similarly labelled antiserum to fibronectin (cold insoluble globulin) an abundance of this protein was also demonstrable (Fig. 7C). In adja- cent sections, suitably stained conventionally for fibrin and with antifibrinogen or antifibronectin, the distribution of fibrin and of fibronectin was almost exactly similar (Figs. 7A-C). This was found despite the fact that these 2 proteins are immunologically unrelated. ${ }^{6}$

Aspirates taken from effusions of many weeks' or months' duration still showed many rice bodies composed almost entirely of fibrin. Variable numbers of mononuclear cells were seen on the surface and

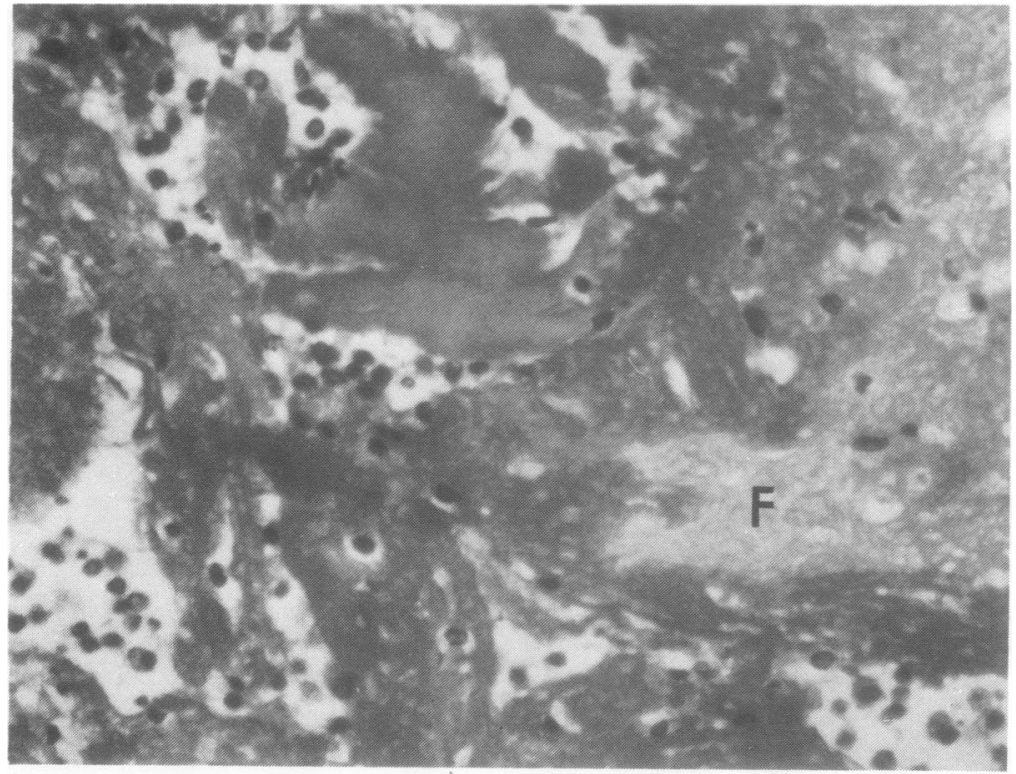

Fig. 4 Rice bodies composed of irregular compacted fibrin admixed with mononuclear cells. Note paler area in large fibrinous rice body where fibrosis is occurring $(F)$. $(H$ and $E, \times 313$ ).

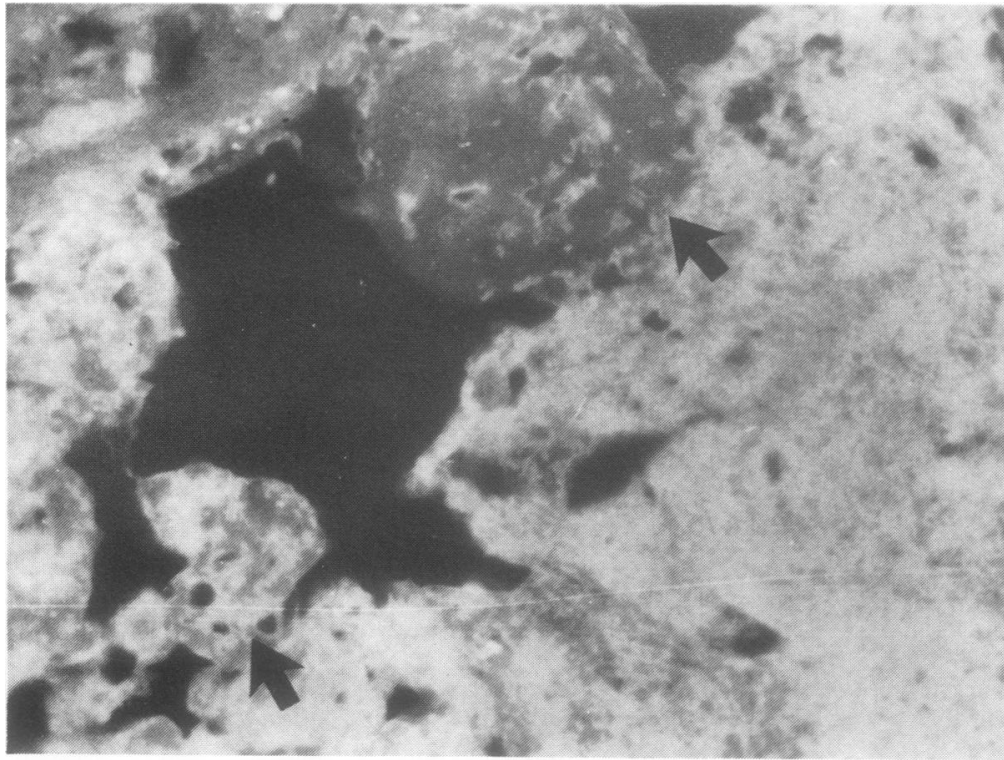

Fig. 5 Unfixed rice bodies examined in ultraviolet light after treatment with fluorescein-labelled antihuman fibrinogen. Specific fluorescence (bright green in original, white in picture) indicates persistence of fibrinogen-related antigens. But note inhomogeneity of reaction in places (arrows). $(\times 200)$ 
enmeshed within the interstices of such rice bodies (Fig. 4). Some rice bodies lacked much evidence of cellular infiltration but showed irregular and diffuse vacuolation, so that they appeared to be composed of a loose and attenuated network of fibrin. The appearance of these particles suggested the reduction of the rice body to a skeletal framework of its original structure, possibly by a fibrinolytic process (Fig. 5).

Other particles stained inhomogeneously, only a portion of the rice body showing the conventional staining reactions or immunoreactivity for fibrin (see Figs. 4, 5, 7A-C). In these instances the remainder of the particles was weakly eosinophilic, staining greyish blue with the MSB method and pink with PTAH. Mononuclear cells were still seen occasionally in such areas. Otherareas of these particles showed the staining reactions of mature collagen in being markedly fuchsinophilic in sections stained with HVG or picropolychrome, staining intensely blue with the MSB method and dark red with PTAH.

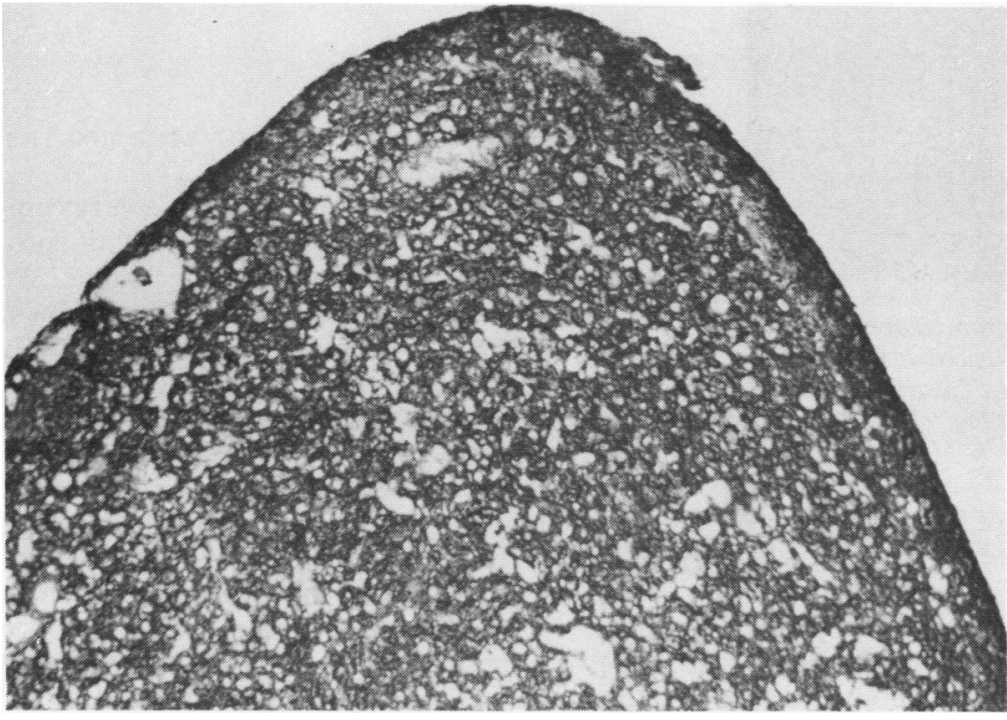

Fig. 6 Portion of fibrinous rice body showing delicate reticular structure composed of network staining as for fibrin surrounding vacuoles of varying size (? rice body undergoing fibrinolytic resorption). (PTAH, × 125).

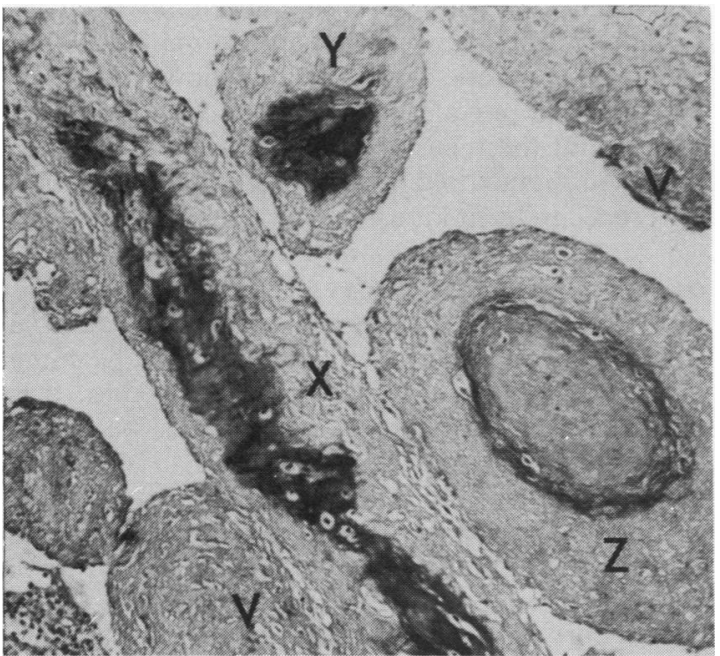

Fig. 7A Rice bodies showing varying stages of fibrosis. Note formation of mature collagen (dark grey in picture, bright blue in original) as solid core in rice bodies $X$ and $Y$ and as ring-like arrangement in centre of rice body $Z$.

Remaining portions of these rice bodies stained greyish-blue in this section (MSB stain) in the original. $(\times 110)$.

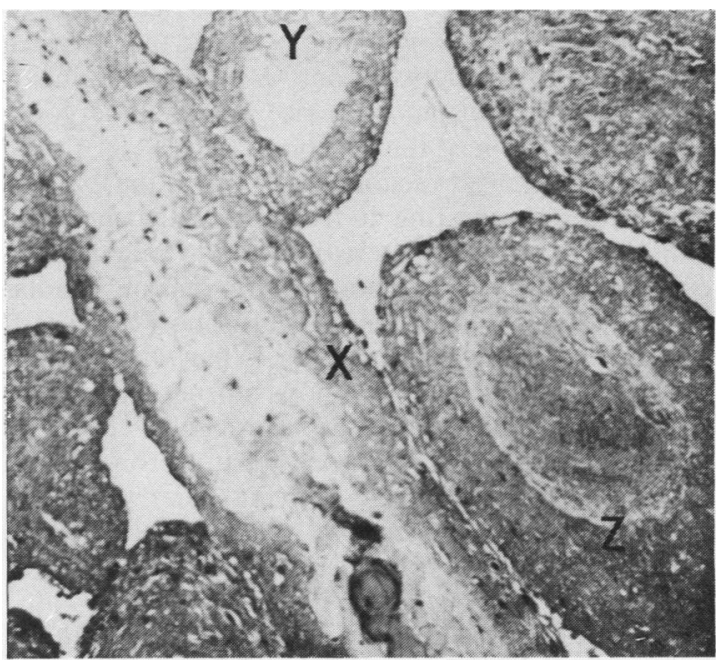

Fig. 7B Same field in adjacent section from same material as in Fig. 7A. Section treated with peroxidase-labelled antihuman fibrinogen. Dark reaction product (brown in original, grey in picture) denotes presence of fibrinogen-related antigen. But note negative reaction of central portions of rice bodies $X$ and $Y$ and of ring-like arrangement in $Z .(\times 110)$. 


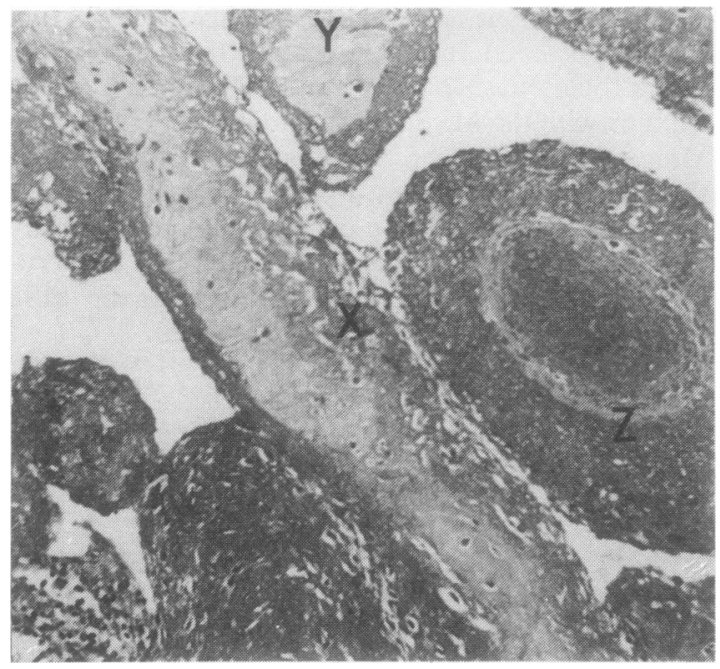

Fig. 7C Same field in another section from same material as in Figs. $7 \mathrm{~A}$ and $7 \mathrm{~B}$. Section treated with peroxidase-labelled antihuman fibronectin. Note similarity of distribution of positively reacting areas to that seen in Fig. $7 B .(\times 110)$.

In some rice bodies this process of fibrosis was seen to be occurring in the 'core' or deep within the substance of the particle (Figs. 7A-C) while, in material aspirated from the most chronically involved joints the particles were often rounded, with smooth margins and a varying proportion of the rice body transformed into a collagenous mass. Some rice bodies of this kind, when suitably stained, showed the presence also of a reticulin network and/or of elastic tissue.

In occasional instances in rice bodies undergoing fibrosis a portion of the rice body reacting as fibrin/ fibronectin showed vacuolation of this at the 'boundary zone' demarcating it from the adjacent area, which gave the characteristic staining reactions of collagen. It is presumed that such regions of vacuolation again represented regions of fibrinolysis preceding fibrous tissue replacement. What was perhaps even more striking was how infrequently such obvious areas of transition were seen. In most instances the junction between fibrin/fibronectin on the one hand and collagen on the other was quite sharp, suggesting a smooth dovetailing of fibrin removal and new fibrous tissue formation in the process of tissue remodelling.

Rice bodies showing early fibrotic change, with the formation of delicate fibres of immature collagen, on immunohistological examination showed fibronectin to be present in such areas. On the other hand other areas (often immediately adjacent) where denser and more mature collagen was present failed to react for fibronectin. As previously reported, ${ }^{6}$ no relation was found between the distribution of fibronectin and elastin, but a close similarity of distribution was noted between fibronectin and argyrophilic fibres identified as 'histological reticulin'.

No instance was encountered in the material examined of amyloid deposits in rice bodies. Sections stained for lipid or for carbohydrates (with the PAS method, alcian blue, or dialysed iron) did not show significant changes. Occasional deposits of haemosiderin and microscopic foci of calcium deposition were encountered in a few instances.

\section{Discussion}

FREQUENCY OF OCCURRENCE OF RICE BODIES IN RA

Our results suggest that rice bodies are a very common accompaniment of rheumatoid synovitis, provided they are sought by an adequate technique. We found them to be present in the effusions from $72 \%$ of our patients. But rice bodies were detected in only $14 \%$ of cases in which simple aspiration was performed, even when a wide-gauge needle was employed. We found an additional $58 \%$ of our cases to have rice bodies in the aspirate only when saline lavage preceded aspiration through a wide-bore needle.

Since in many instances much of the particulate material recovered was quite large in particle size (Fig. 1), it seems probable that rice bodies would have been detected in few if any of our cases if aspiration had been attempted, without preliminary lavage, through a fine-gauge needle in the manner widely used for diagnostic aspiration of synovial fluid. We feel that the prevalent (but in our view mistaken) view about the relative rarity of occurrence of rice bodies in rheumatoid joints in fact derives from this difference in technique.

ORIGIN AND DEVELOPMENT OF RICE BODIES Our histological and immunohistological observations supplement the scanty microscopic examinations previously published on rice bodies from patients with RA, that is, the 2 cases studied by Albrecht et al. ${ }^{2}$ and the 7 patients in the series reported by Berg et al. $^{3}$ In agreement with these authors our findings suggest that there are progressive changes in the structure of rice bodies. However, access to patients seen over a wider range of the disease process and to a much larger volume of material has allowed us to observe that rice bodies may progress to a degree of maturity resembling that of established connective tissue in consisting of coarse collagenous fibres, reticulin, and elastin. To our knowledge development to this degree of organisation has not previously been recorded in 
rheumatoid rice bodies-presumably because relatively so few specimens have been extensively examined histologically.

It has been suggested that rice bodies originate from detached fragments of degenerating synovial villi. ${ }^{12}$ In synovial fluid from chronically involved joints we found occasional synovial fragments (Fig. 1) along with other detritus derived from joint structure, such as slivers of cartilage and minute spicules of bone. In occasional instances rounded but wellvascularised structures (presumably therefore originating from synovium) were seen, covered with a fibrin coat of variable thickness (Fig. 3). Nevertheless, we consider that the earliest rice bodies are predominantly fibrinous in nature and formed independently of synovial fragments, though whether the entrapped mononuclear cells are leucocytes derived from the blood or synovial cells is difficult to determine (also see below).

In fibrinous particles, free in rheumatoid synovial fluid, we have found fibronectin also to be present. In this respect such rice bodies resemble fibrinous deposits ('fibrinoid') adherent to the synovium ${ }^{6}$ or plasma clots formed in vitro, in which fibronectin binds to fibrin. ${ }^{13}$ Coprecipitation of fibronectin and fibrinogen also occurs in the presence of heparin and other glycosaminoglycans, especially at low temperatures. ${ }^{14}$ The possibility was considered that glycosaminoglycans released into the synovial fluid from eroded cartilage might play some part in precipitating fibrin and fibronectin to form rice bodies. Conventional histochemical stains for glycosaminoglycans on rice bodies did not support this possibility.

Our previous work has established that fibronectin is locally synthesised by synovial cells and that the level in synovial fluid is often higher than that in plasma in RA. ${ }^{15}$ This intra-articular production of fibronectin, which is markedly adhesive in its physical properties, ${ }^{16}$ probably not only favours the initial formation of insoluble fibrin/fibronectin precipitates but also assists in effecting the aggregation of particles and their increase in size, thus influencing rice body formation.

\section{PERSISTANCE OF RICE BODIES IN INFLAMED JOINTS}

There has been much interest and controversy as to why fibrinous deposits persist in joints. On the one hand in inflamed joints in which large numbers of phagocytic cells (both blood macrophages and phagocytic type A synovial cells) gain access to the synovial fluid it can be envisaged that the cellular uptake of particulate fibrinous deposits and their eventual 'digestion' and disposal would occur. An opsonic role for fibronectin in regard to this cellular disposal mechanism has been proposed. ${ }^{17}$
On the other hand it is well established that not only all the necessary blood coagulation components required to give rise to fibrinous deposits, but also those of the blood fibrinolytic system (concerned with the resolution of such deposits), insude into synovial fluid in active joint disease..$^{121}$ It would be expected therefore that this humoral mechanism would complement or reinforce the cellular removal mechanism referred to above. Since our results indicate that early rice bodies contain both fibrin-related and fibronectin-related antigens, it is interesting to note that fibronectin is known to be as susceptible as fibrin to plasmin digestion ${ }^{22}$ and to the action of neutral proteases from polymorphonuclear leucocytes. ${ }^{23}$

While the appearance of some rice bodies was consistent with the particle undergoing fibrinolysis (see Fig. 4), in other rice bodies abundant fibrinous material was still present, and the majority of particles showed condensation rather than attenuation of their structure. The occurrence and persistence of fibrinous rice bodies probably depends on the balance between the rate of production and maturation of these structures and the rate of their disposal by phagocytosis and/or fibrinolysis. With regard to plasmin activity, there is argument as to whether fibrinous deposits persist because of reduction of plasmin activators or increased amounts of antiplasmins or antiactivators in rheumatoid synovial fluid. ${ }^{20212426}$ It has been reported that urokinase is effective in vitro in promoting the digestion of fibrinous rice bodies and also in vivo in suitable cases. ${ }^{11}$

\section{LATER STAGES IN THE EVOLUTION OF RICE BODIES}

Earlier reference has been made to the possible role of the type A synovial cell in phagocytosing and disposing of fibrinous deposits. It seems possible that the type B cells, which show many of the functional characteristics of fibroblasts, may be concerned in the establishment and development of rice bodies. This is because these cells synthesise both fibronectin and collagen. It may be assumed that it is such cells, entrained in some of the rice bodies we have examined, which are responsible for the secretion of fibronectin and immature collagen and for their later replacement by mature collagen. Particles undergoing this sequence of changes would appear to correspond to the type II rice bodies described by Berg et al. ${ }^{3}$

The codistribution of fibronectin with immature collagen in the earlier stages of fibrosis of rice bodies confirms our earlier observations. ${ }^{6}$ It is presumably accounted for by the high binding affinity of fibronectin for certain varieties of collage ${ }^{27}$ as well as for fibrin. However, in those areas of rice bodies com- 
posed predominantly of more mature, coarse collagen fibronectin could no longer be detected by the immunohistological techniques used. The reason for this loss of binding capacity for fibronectin by mature collagen is not apparent.

Some rice bodies, undergoing conversion to fibrous nodules, resemble connective tissue elsewhere in the body in containing argyrophilic reticulin fibres and/ or elastic tissue. As observed in other situations, ${ }^{28}$ the distribution of fibronectin in such rice bodies was unrelated to that of elastin but closely similar to that of histologically defined reticulin.

\section{SIGNIFICANCE OF RICE BODIES}

It has been shown that fibrin can serve as an irritant and a potent stimulus to fibrogenesis when implanted in serous cavities. ${ }^{29}$ When instilled into joints, Dumonde and Glynn ${ }^{30}$ showed that even autologous fibrin can persist and evoke a persistent arthritis in a small proportion of animals. In man Glynn ${ }^{31}$ has suggested that persistent fibrin deposits may provide a continuous stimulus to antibody formation to other altered bodily constituents, possibly including products of inflammation, in rheumatoid joints. Rice bodies may contribute in this manner to the chronicity of synovitis in RA.

Indirect support for this proposition is provided by our observation that, conversely, effective removal of rice bodies by lavage and aspiration in itself produces marked clinical improvement in affected joints. Alternatively it may be argued that this result is no more than can be expected from application of the well-established surgical principle of ensuring effective debridement of inflamed tissues to assist healing.

However, where it is proposed to attempt to obtain a similar result by the alternative procedure of preliminary instillation of fibrinolysis-promoting agents such as urokinase, our findings suggest that preliminary lavage, aspiration, and histological examination are advisable. ${ }^{11}$ This is because rice bodies which have undergone further maturation into partially fibrous structures will not respond to such treatment. For this reason, and also as a useful accessory means of decreasing joint disability, we recommend lavage, aspiration, and microscopical examination of rice bodies in rheumatoid arthritis.

\section{References}

${ }^{1}$ Riese H. Die Reiskörpchen in tuberculös erkranken synovalsäcken. Detsch Z Chir 1895; 42: 1-99.

2 Albrecht M, Marienetti G V, Jacox R F, Vaughan J H. A biochemical and electron microscopy study of rice bodies from rheumatoid patients. Arthritis Rheum 1965; 8: 1053-63.

3 Berg E, Wainwright R, Barton B, Puchtler H, McDonald T. On the nature of rheumatoid rice bodies. An immunologic, histochemical and electron microscope study. Arthritis Rheum 1977; 20: $1343-49$.
}

4 American Rheumatism Association. Diagnostic criteria for rheumatoid arthritis. 1958 revision. Ann Rheum Dis 1959; 18: 49-53.

${ }^{5}$ Saint-Marie G. A paraffin embedding technique for studies employing immunofluorescence. J Histochem Cyochem 1962; 10: $250-6$.

${ }^{6}$ Scott D L, Wainwright A C, Walton K W, Williamson N. Significance of fibronectin in rheumatoid arthritis and osteoarthrosis. Ann Rheum Dis 1981; 40: 142-53

${ }^{7}$ Miller P J. An elastin stain. Med Lab Technol 1971; 28: 148-9.

${ }^{8}$ Gordon $\mathrm{H}$, Sweet $\mathrm{H} \mathrm{H}$. A simple method for the silver impregnation of reticulin. Am J Pathol 1936; 12: 545-51.

${ }^{9}$ Lendrum A C, Fraser D S, Slidders W, Henderson R. Studies on the character and staining of fibrin. J Clin Pathol 1962; 18: 401-13.

${ }^{10}$ Herovici C. Le picropolychrome. Technique de coloration histologique destinée à l'étude du tissu conjonctif normal et pathologique. Rev Fr Etud Clin Biol 1963; 8: 88-9.

11 Williamson N, Popert A J, Williamson T J, El-Badawy S A, Wainwright A C. Fibrin deposition in rheumatoid joints and the use of intra-articular urokinase. Proceedings of IXth European Congress of Rheumatology (abstr). Wiesbaden, 1979: 212.

12 Fassbender H G. Pathology of the Rheumatic Diseases. Transl Loewi G. Berlin: Springer-Verlag, 1975: 114-5.

13 Ruoslahti E, Vaheri A. Interaction of soluble fibroblast surface antigen with fibrinogen and fibrin. Identity with cold insoluble globulin of human plasma. J Exp Med 1975; 141: 497-501.

14 Mosesson M W. Structure of human plasma cold insoluble globulin and the mechanism of its precipitation in the cold with heparin or fibrin-fibrinogen complexes. Ann NY Acad Sci 1978; 312: 11-30.

${ }^{15}$ Scott D L, Farr M, Crockson A P, Walton K W. Synovial fluid and plasma fibronectin levels in rheumatoid arthritis. Clin Sci in press.

${ }^{16}$ Yamada K M, Olden K. Fibronectins-adhesive glycoproteins of cell surface and blood. Nature 1978; 275: 178-84.

${ }^{17}$ Saba T M, Blumenstock F A, Weber P, Kaplan J E. Physiologic role of cold insoluble globulin in systemic host defense: implications of its characterisation as the opsonic $\alpha_{2}$-surface binding glycoprotein. Ann N Y Acad Sci 1978; 312: 43-55.

${ }^{18}$ Astrup T, Sjölin K E. Thromboplastic and fibrinolytic activity of human synovial membranes. Proc Soc Exp Biol Med 1958; 97 : 852-3.

${ }^{10}$ Barnhart M I, Riddle J M, Bluhm G B, Quintana C. Fibrin Promotion and lysis in arthritic joints. Ann Rheum Dis 1967; 26: 206-18.

20 Caughey E D, Highton T C. Components of the fibrinolytic system in synovial joints: normal bovine compared with normal and abnormal human synovial joints. Ann Rheum Dis 1967; 26: 297-305.

21 Anderson B, Gormsen J. Fibrinolytic and fibrin stabilizing activity of synovial membranes. Ann Rheum Dis 1970; 29: 287-93.

${ }^{22}$ Blumberg P M, Robbins P W. Effect of proteases on activation of resting chick embryo fibroblasts and on cell surface proteins. Cell 1975; 6: 137-47.

${ }^{23}$ McDonald J A, Baum B J, Rosenberg D M, Kelman J A, Brian S C, Crystal R G. Destruction of a major extracellular adhesive glycoprotein (fibronectin) of human fibroblasts by neutral proteases from polymorphonuclear leukocyte granules. Lab Invest 1979; 40: 350-7.

24 Putti L B A van de, Noordhoek Hegt V, Overbeek T A. Activators and inhibitors of fibrinolysis in rheumatoid and nonrheumatoid synovial membranes. Arthritis Rheum 1977; 20: 671-8.

${ }^{25}$ Berger H, Fleming P R, Voorhees P R. Secretion of plasminogen activator by rheumatoid and nonrheumatoid synovial cells in culture. Arthritis Rheum 1977; 20: 1198-205.

${ }^{26}$ Clemmensen I, Donde R, Anderson R B. The primary plasmin inhibitor in rheumatoid synovial fluid. Arthritis Rheum 1977; 20: 1354-58. 
${ }^{27}$ Engvall E, Ruoslahti E. Binding of soluble forms of fibroblast surface protein, fibronectin, to collagen. Int J Cancer 1977; 20: 1-5.

${ }^{28}$ Linder E, Stenman S, Lehto V P, Vaheri A. Distribution of fibronectin in human tissues and relationship to other connective tissue components. Ann N Y Acad Sci 1978; 312: 151-9.

${ }^{29}$ Curran R C. Mucopolysaccharides and collagen formation in atherosclerosis. In: Chalmers D G, Gresham G A. eds. Biological Aspects of Occlusive Vascular Disease. Cambridge: Cambridge University Press, 1964: 76-83.

${ }^{30}$ Dumonde D C, Glynn L E. The production of arthritis in rabbits by an immunological reaction to fibrin. BrJ Exp Pathol 1962; 43: 373-83.

${ }^{31}$ Glynn L E. The chronicity of inflammation and its significance in rheumatoid arthritis. Ann Rheum Dis 1968; 27: 105-21. 